\title{
Tempo Presente e História Ambiental: a contemporaneidade do desastre do Césio-137 (Goiânia, mais que 1987)
}

\begin{abstract}
Resumo
Neste artigo, discutimos encontros de contemporaneidade entre História Ambiental e História do Tempo Presente, tendo a história de um desastre sociotécnico como ponto de partida e de chegada: a contaminação de Césio-137 em Goiânia, Brasil, em 1987. Ele nos permite questionar o estatuto do ser contemporâneo, o que significa pensar tempo presente em História Ambiental e o que significa pensar tempo contemporâneo em História do Tempo Presente. A problematização das práticas de nomeação e caracterização do tecnodesastre de Goiânia nos impeliu a ler relatos oriundos tanto da imprensa escrita como de imagens e de documentários produzidos ao longo dos 30 anos de permanência do desastre na memória nacional, em cotejo com produções teórico-metodológicas sobre o tempo na História.
\end{abstract}

Palavras-chave: História Ambiental. Desastres. Brasil. História do Tempo Presente.

\section{Jó Klanovicz}

Doutor em História pela Universidade Federal de Santa Catarina (UFSC). Professor da

Universidade Estadual do Centro-Oeste (UNICENTRO).

Guarapuava - PR - BRASIL

klanov@gmail.com

orcid.org/0000-0002-5110-9028

\section{Maíra Kaminski da Fonseca}

Doutoranda do Programa Interdisciplinar em Ciências Humanas da Universidade Federal de Santa Catarina (UFSC).

Florianópolis - SC - BRASIL

mahkaminski@gmail.com

orcid.org/0000-0001-7582-9559

\section{Para citar este artigo:}

KLANOVICZ, Jó; FONSECA, Maíra Kaminski da. Tempo Presente e História Ambiental: a contemporaneidade do desastre do Césio-137 (Goiânia, mais que 1987). Tempo e Argumento, Florianópolis, v. 11, n. 26, p. 201 - 228, jan./abr. 2019. 


\title{
History of the Present, and Environmental History: the Cesium-137 disaster contemporaneity (Goiania, more than 1987)
}

\begin{abstract}
In this article, we discuss encounter of 'contemporaneity' between Environmental History and History of the Present, through the history of the Cesium-137 Radioactive Disaster of Goiania, Brazil, 1987 as a starting point and arrival point. It allows us to read the status of the 'contemporary', what is the meaning of the term 'present' in Environmental History, and what is the meaning of the term 'contemporary time' in the History of the Present. The problematization of the naming and characterization practices of Goiania's technodesastre impelled us to read reports from written press, images and documentaries produced during the 30 years of permanence of the disaster in national memory, in comparison with scientific productions about the same period.
\end{abstract}

Keywords: Environmental History. Disaster. Brazil. History of the Present.

Neste artigo, buscamos discutir encontros possíveis de contemporaneidade entre História Ambiental (HA) e História do Tempo Presente (HTP), tendo a história de um desastre sociotécnico como ponto de partida e de chegada: a contaminação de Césio-137 em Goiânia, Brasil, em 1987. Acreditamos que o evento de Goiânia sintetiza a dimensão de contemporaneidade que tanto HA como HTP carregam na sua constituição institucional, acadêmica e teórico-metodológica. Ele nos permite questionar, de maneira renovada, o que significa ser contemporâneo em História do Tempo Presente, e o que significa pensar tempo presente em História Ambiental. 
Embora haja aproximações e até convergências entre HA e HTP, com potencial de investigações renovadas para o futuro, ainda não é possível verificar diálogos mais tangíveis entre elas. O historiador sueco Sverker Sörlin (2011) pontuou esse fato, salientando que o elemento fundamental e comum a ambas as áreas seria a contemporaneidade de temas, de problemas e de abordagens. A contemporaneidade garantiria, também, a oportunidade, a relevância e a capacidade desses campos de dialogar com outras comunidades epistêmicas (SÖRLIN, 2011, p. 612). Acreditamos, nesse sentido, que o estudo de desastres constitui uma das áreas nas quais HA e HTP convergem.

Para trabalhar com o assunto, então, atentamos para a discussão da história como estrutura de fluxos de eventos e tempo, tendo a contemporaneidade como junção desses dois polos, num primeiro momento; depois, apresentamos problemas ligados ao saber histórico refletido na HA e na HTP, buscando entrelaçar as preocupações da contemporaneidade de desastres (por meio de relatos transtemporais do Césio 137) com o tempo presente na História Ambiental, apresentando esse evento como tema contemporâneo, no sentido de articular fluxo de evento e tempo.

A problematização das práticas de nomeação e caracterização do tecnodesastre de Goiânia nos impeliu a ler relatos oriundos tanto da imprensa escrita como de imagens e de documentários produzidos ao longo dos 30 anos de permanência do desastre na memória nacional, claro que não nos prendendo em toda a produção realizada sobre ele, mas em aspectos-chave que apareceram em produções culturais específicas.

Ao longo dos anos 1980, a mídia escrita constituía importante instrumento de formação de opinião pública no Brasil, e pensar as narrativas impressas da grande mídia (entendendo-a, estritamente aqui, na forma de revistas impressas de circulação nacional) acerca do desastre do Césio-137 representa uma oportunidade interessante para discutir as formas de apropriação realizadas pela própria imprensa sobre o evento, além de permitir inferir sobre o próprio papel do jornalismo no trato de temas polêmicos, como o uso de tecnologia nuclear, ainda mais em um país que buscava, no período, participar do seleto grupo de nações que tinham possibilidade de desenvolver armas nucleares. Nos anos 2000, há outras primazias da imagem, bem como outros olhares em torno de 
eventos e da forma como os relatamos publicamente, o que remonta a novos processos de enquadramento de narrativas que levam, por conseguinte, a novas moldurações, especialmente no âmbito televisivo (KLIPP, 2002, p. 209). Assim, além da narrativa referente ao ano do acidente, prestamos atenção aos "aniversários" do desastre (25 anos; 30 anos), com intuito de problematizar as práticas de memória e/ou esquecimento, ao quê dar visibilidade e o que excluir das narrativas. Essa extensão é necessária, na medida em que só em 2013 é que a justiça brasileira deu o primeiro parecer favorável, em última instância, à indenização estatal a uma das inúmeras vítimas do acidente.

\section{História como estrutura, contemporaneidade como junção de eventos e temporalidades}

Por um momento, quero suspender HA e HTP, para pensar história como estrutura, ou melhor, história como sendo fluxo de eventos e curso do tempo. Só a partir de uma história como fluxo é que é possível pensar as relações entre passado e presente, que formalizar, no plano abstrato, o agora ou a contemporaneidade, processo e ruptura, mudança e continuidade, com suas nuances e problemas (SCHÄFER, 2018; VIEREGG, 2015).

Ao longo do século XX, do entreguerras aos emaranhamentos da Guerra Fria e de lutas cada vez maiores sobre o estatuto e o papel da História frente às crises socioambientais, políticas, econômicas e simbólicas do período, a natureza da própria História veio à tona do debate acadêmico e filosófico, especialmente no que se refere à ideia de contemporaneidade, principalmente na sua dimensão estética e ética.

Walter Benjamin (1940) refletia constantemente sobre o tema, observando a relação dialética entre passado e presente e a necessidade de se construir o contemporâneo a partir, justamente, da reconhecibilidade dos distintos "agoras". Para ele, a relação do presente com o passado seria eminentemente temporal, mas a relação do que aconteceu com o agora seria totalmente dialética e essas imagens dialeticamente construídas é que fundamentariam a própria história (SMITH, 2016).

Estamos falando de uma preocupação fundamental à História que é o estatuto da interpretação na construção do conhecimento histórico ou, como Hans Gadamer 
observa, da ideia de "senso" ou "tato" (GADAMER, 1999), constituídos na esfera do tempo e do espaço. A contemporaneidade, assim, estaria na base da atualidade ou da continuidade atual na descontinuidade. Continuidade e descontinuidade seriam determinantes históricos ou espaço-temporais de algo que, de fato, não conhecemos. $O$ que garantiria nosso senso histórico e nossa possibilidade de estabelecer passado e presente seria nossa capacidade atual de estarmos bem posicionados na frente de uma decisão sobre o próprio passado, sobre o que narrar, o que selecionar, o que ignorar ou esquecer, e como e o que interpretar (GADAMER, 1999).

A ideia de que a existência humana e a orientação reflexiva sobre ela percorrem o próprio fluxo da história e a constituem ao mesmo tempo, estabelece a própria história como estrutura temporal de acontecimentos e campo de conhecimento. Essas nuances ocupam lugar no cursus temporum que é a própria história, a estrutura na qual o curso dos eventos toma lugar no tempo, para utilizar uma expressão do historiador Nathan Rotenstreich (1987). A função de quaisquer historiadores e historiadoras seria, nesse sentido, identificar o cursus e o tempus, delimitar quais ações e eventos de relevância existem neles a partir de uma mirada privilegiada (o ser presente, já apresentado em Gadamer), descrever processos e percorrer significados possíveis na respectiva estrutura.

Uma discussão mais centrada na História foi proposta, então, por Nathan Rotenstreich, na continuidade de obras como Tempo e Significado na História, que foi traduzido para o inglês em 1987. Para ele, curso e tempo são dois conceitos que atingem diretamente a história na medida em que apresentam desafios ligados à escala espaçotemporal de leitura, bem como ao escopo, às escolhas, às abordagens possíveis do conhecimento histórico (que, diga-se de passagem, não é restrito às ciências humanas, nem à história stricto sensu).

Problematizar o curso e o tempo de maneira separada implica bifurcar a leitura de um fenômeno. Por um lado, eventos acontecem e são percebidos individualmente. Por outro, a elaboração de uma narrativa capaz de aproximar eventos e dar a eles a ideia de fluxo exige olhar mais amplo. Rotenstreich (1987) salienta, dessa forma, que seres humanos não são apenas indivíduos isolados e que qualquer interpretação da história tem de considerar tanto processos que envolvem seres humanos como humanidade, por um 
lado, mas também o impacto dos processos totais em escalas individuais. Uma tensão profunda entre a interpretação da história a partir das limitações do cursus surge no âmbito da própria história-estrutura: devemos assumir que há objetivos transindividuais na escrita da história, excluindo o que não é humano da leitura espaço-temporal, ou apenas colocando-a como pano de fundo, ou devemos escolher uma escrita que considere objetivos mais amplos, humanos e não apenas individuais ou grupais nessa escrita?

Como já citado, para identificar esse curso, historiadores e historiadoras precisam limitá-lo, uma vez que sua preocupação básica e fundamental é com a escrita das ações e dos eventos humanos. Fenômenos naturais como condições climáticas ou acontecimentos esporádicos como terremotos, tornam-se eventos históricos na medida em que seres humanos ajustam-se a eles ou os integram, respondendo ou antecipando-se a eles. No fim, o cursus temporum está limitado a processos que ocorrem dentro da órbita do humano. Assim, a relação com o tempo é uma forma ou horizonte de sucessão. Para Rotenstreich, então, isso significa que os seres humanos, na experiência diária, são confrontados com o fato de que o fluxo ou a sucessão temporal existe, e que o evento "b" segue o evento "a".

A sucessão implica descrever um fenômeno numa relação de antes e depois, um depois do outro, por meio de outros elementos fundamentais como transição e o esclarecimento das relações que a constituem. Por outro lado, o discernimento da relação de reciprocidade entre os estágios do processo implica no reconhecimento do processo em si (ROTENSTREICH, 1987, p. 19). Para Rotenstreich (1987), seria impossível discutir o tempo da história a partir da imersão total no processo, pois o tempo da história não é o processo histórico em si. Uma das poucas possibilidades de discuti-lo seria discernir tempo não como processo, uma vez que a reação de tempo implica a distinção entre humanos ou sujeitos de discernimento, e tempo-objeto de discernimento (ROTENSTREICH, 1987, p. 19).

Nesse sentido, o ser humano ocupa um papel dual na relação com o fluxo dos eventos no tempo: vive dentro dele e, ao mesmo tempo, se move com o processo; mas também observa o processo e se destaca dele. Há, dessa forma, uma intencionalidade 
profunda para com o processo todo, uma vez que a condição de percepção do tempo não reside no engajamento existencial com o objeto, mas com a tentativa de discerni-lo conceitualmente.

A história como estrutura não significa, contudo, uma espécie de alicerce sobre o qual tenha que ser assentada uma construção com apenas um padrão ou modelo; ela permite múltiplas apropriações estruturais, que seriam metaforicamente as temporalidades e relações entre eventos que nelas acontecem e que têm a potencialidade de serem narrados a partir de diferentes pontos de vista. Como ocorrência de eventos no tempo, a história não residiria apenas na dimensão temporal, mas na correlação entre o tempo e a reflexão sobre ele, tempo e explanação do tempo e de eventos.

Entre defensores dessa perspectiva, está Doris Gerber (2014) que, ao trabalhar com a explanação nas assim chamadas Ciências Especiais (História e Biologia), pontua que a História não pode ser mero fluxo de acontecimentos nem sua crônica. Segundo ela,

mesmo o cronista ideal que pudesse saber todos os acontecimentos no momento em que eles acontecessem, e que tivesse o dom de transcrevêlos naquele instante, não teria a capacidade de contar uma história de imediato, uma vez que não seria capaz de estabelecer as relações historicamente relevantes entre os eventos. (GERBER, 2014, p. 217)

A autora está preocupada, ao utilizar um cronista ideal ficcional, em estender o problema da explicação histórica para outros campos do conhecimento e para dentro do próprio conhecimento histórico como fator-chave da correlação tempo-reflexão. Mas a proposição fundamental de Doris Gerber (2014) reside em outro lugar: como a narrativa da história reside no tempo e é, simultaneamente, fruto dele e sobre ele em relação aos acontecimentos, uma explanação histórica sempre acontece na mudança do curso dos eventos, simplesmente devido ao que acontece depois (no presente). Isso explica porque o significado histórico de eventos passados pode mudar com o curso do tempo (GERBER, 2014).

Os caminhos do tempo (englobando aqui conceitos como temporalidade, periodização, sucessão, chronos, kairós e aeôn) constituem a espinha dorsal da história e 
de suas ambiguidades. Na medida em que distanciamentos e encontros foram acontecendo entre as modalidades temporais na construção do próprio conhecimento histórico, bem como foram surgindo especialidades históricas que de maneira independente, porém trans-histórica, propunham novas temporalidades e periodizações, a relação entre tempo e significado na história adquiriu maior sofisticação.

A história contemporânea (na versão alemã da Zeitgeschichte ou da Contemporary History) viu-se envolta por uma polêmica fundamental em torno do tempo, especialmente sobre a contemporaneidade dos eventos. Um texto clássico elaborado pelo historiador Geoffrey Barraclough como documento de trabalho no âmbito do Grupo de História Recente de Oxford, em 1956, apontava para as diferenças e os desafios de se pensar a imediatez, a contemporaneidade, o presente no campo da história. Barraclough observava que a

História do tipo tradicional começa num dado ponto no passado - a Revolução Francesa, por exemplo, a Revolução Industrial ou o assentamento de 1815 - e trabalha sistematicamente para a frente, traçando um desenvolvimento contínuo ao longo das linhas de evolução de um dado ponto de partida. A história do presente segue - ou deveria seguir - um procedimento contrário. Ambos os métodos nos levam a um passado remoto, mas um passado diferente. (BARRACLOUGH, 1969, p. 17-18)

O autor continua o raciocínio observando que uma história do presente começa quando os problemas do mundo de hoje ganham forma visível (BARRACLOUGH, 1969, p. 18) e, nesse sentido, não se trata de uma história que possa ser rotulada de antemão, pois é sempre provisória, ambígua, mas também colorida. O que Geoffrey Barraclough pontuava ao posicionar-se em favor de uma história mais colorida, inexata e por vezes sem um sentido bem estabelecido (BARRACLOUGH, 1969, p. 18) era a necessidade de a comunidade de história abrir-se a novas maneiras de fazer e de pensar historicamente períodos que estavam contemporaneamente em transição.

Não é gratuito o esforço do autor, então, em identificar processos em curso no momento em que pesquisava a temporalidade do contemporâneo na sua história (a edição do livro An Introduction to Contemporary History trabalha justamente com temas abertos como o papel da ciência e da tecnologia no mundo pós-Segunda Guerra Mundial, 
o fortalecimento das teorias comunistas de sociedade, o anti-ocidentalismo na Ásia e na África). É o pós-Segunda Guerra que, justamente, desperta a comunidade de história para o tempo presente, para a escrita de uma história imediata, de processos ou eventos inacabados (AREND, MACEDO, ROUSSO, 2009).

A contemporaneidade, nesse sentido, veio a ser contemplada conceitualmente como a "junção com o tempo", não apenas no que diz respeito à sequência temporal, mas no que se apropria de e nele. A contemporaneidade não pode ser interpretada, assim, como mera atualidade ou história atual numa perspectiva mais pragmática e, sim, como um espaço-tempo-lugar de conexões recíprocas entre o atual e o não atual, entre os pontos estabelecidos na estrutura-história dos eventos e seus tempos, articulando, mesmo, o ser presente (KOMEL, 2014).

Dean Komel (2014) observa, então, que a definição da contemporaneidade está diretamente ligada ao entendimento da condição contemporânea como sendo comtemporaneidade. Em outros termos, ela traz de maneira unificada a multidão de diferentes temporalidades que coexistem num mesmo momento histórico, na forma de uma interconexão de diferentes tempos e experiências do tempo, de intensidade planetária (KOMEL, 2014). A contemporaneidade, nesse sentido, refere-se a uma complexidade temporal, apresentando interconexões, num mesmo espaço cultural, de culturas heterogêneas geradas em diferentes trajetórias, em diferentes escalas, localidades, que vêm a afetar a experiência-tempo de indivíduos e de grupos (SMITH, 2016).

\section{Da História Ambiental à História Ambiental dos Desastres}

$\mathrm{Na} \mathrm{HA}$, a materialização da contemporaneidade reside na ênfase que grande parte de quem trabalha na área tem dado a temas ambientais do presente ou do passado recente, com vistas a identificar emergências e narrativas, especialmente de problemas ambientais atuais (SÖRLIN, 2011). Nesse sentido, é preciso localizar o campo da HA na produção de História no final do século XX. 
O historiador José A. Pádua (2010) expôs com precisão a história ambiental, observando sua institucionalização nos anos 1970, especialmente com o surgimento da American Society for Environmental History, em 1977 (PÁDUA, 2010, p. 81). Trata-se de uma forma de fazer história que surgiu, como a conhecemos agora, em momento de compatibilização entre os movimentos sociopolíticos das ruas, entre eles os ambientalismos e as preocupações acadêmicas'. Assim, é impressionante pontuar a capacidade que o campo teve de conquistar alguns espaços, primeiro na língua inglesa, depois na América Latina e em outras regiões do planeta.

Em linhas gerais, a partir especialmente de obras como a do historiador Donald Worster (tais como Dust Bowl: The Southern Plains in The 1930s (publicada em 1979) ou The Ends of the Earth: Perspectives in Modern Environmental History, publicada em 1988), a HA foi sendo delineada como uma leitura nivelar e inter-relacionada da história a partir da combinação de dados da natureza propriamente dita, orgânica e inorgânica, "incluindo aí o organismo humano em sua relação com os diferentes ecossistemas" - ou seja, o primeiro nível de análise -, dados da constituição socioeconômica das sociedades e sua inter-relação necessária com determinados espaços geográficos (segundo nível) e as dimensões cognitivas, mentais e culturais da existência humana (terceiro nível) (PÁDUA, 2010, p. 95). O ambiente(al) é tomado, assim, como uma categoria entendida como a síntese das dimensões naturais e construída do mundo palpável (BUELL, 2001).

O que há de novo nessa forma de relacionar os três níveis e dimensionar o ambiente como categoria? De início, e quase de forma peremptória, conforme aponta José A. Pádua (2010), deve-se partir da ideia de que a questão ambiental é uma questão moderna e que precisa ser entendida em sentido amplo, já que a relação com o ambiente coloca um problema radical e inescapável para a continuidade da vida humana, e não está

\footnotetext{
${ }^{1} \mathrm{O}$ campo não é inteiramente novo nem necessariamente derivado do ambientalismo político. Conforme observa Andrew Isenberg (2014), embora o movimento ambientalista tenha dado sentido à HA, os vínculos intelectuais do campo podem ser identificados ainda no século XIX, em obras como a de George P. Marsh (Man and Nature, 1864) ou de Frederick J. Turner. Nos anos 1930, trabalhos como The Great Plains, de Walter P. Webb ou a própria orientação da recém-criada revista Annales d'histoire économique et sociale rejeitavam uma história orientada aos eventos. Isenberg observa que "todas essas escolas articularam, de um modo ou de outro, histórias de sociedades humanas interagindo com a natureza", com enfoque interdisciplinar (ISENBERG, 2014, p. 5).
} 
relacionada apenas com as consequências da grande transformação urbano-industrial, mas, também com uma série de outros processos macro-históricos (PÁDUA, 2010, p. 83).

No primeiro nível, a sugestão de que devemos atentar para as transformações do mundo biofísico ao longo do tempo, buscando reconstituir os ambientes do passado, tarefa que tem muitas nuances interpretativas, desde leituras como a de Fernand Braudel, em 1949, contrapondo uma história quase imóvel do ambiente à velocidade das mudanças sociais até outras leituras que rompem radicalmente com essa perspectiva (PÁDUA, 2010, p. 95). É o caso de algumas abordagens sobre desastres na história ambiental nas quais a agência do mundo natural se demonstra no caráter repentino de eventos como terremotos ou outros fenômenos (LEHMKUHL; WELLENREUTHER, 2007). A “segunda natureza”, ou seja, a cultura material, os meios tecnológicos produzidos pela ação humana compõem o segundo nível de uma leitura de HA, o mundo socioeconômico e suas inter-relações com o espaço. Por fim, quando se fala nas dimensões cognitivas, mentais e culturais da existência humana, está-se observando o comportamento social dos seres humanos em relação ao mundo natural, assim como a própria estruturação socioeconômica da vida coletiva, que passa pelas visões de natureza e dos significados da vida humana (PÁDUA, 2010, p. 95).

A contemporaneidade da HA é, nesse sentido, uma das questões ambientais, da ecologização da política, de mudanças epistemológicas profundas nas ciências, especialmente a partir do final da Segunda Guerra Mundial, em paralelo à crítica da ortodoxia das ciências (LATOUR, 2004), à emergência da complexidade como abordagem das relações entre natureza e cultura (MATURANA, 2001), à necessidade de novas formas científicas e relacionais para trabalhar com essas relações, o que autoras como Donna Haraway denominam de natucultura (HARAWAY, 2003). É assim que podemos discernir uma fase de síntese no século XXI, na qual o ambiente tornou-se uma preocupação central da política e do público geral (SÖRLIN, 2011, p. 614).

Como esse foco sobre temas contemporâneos e recentes afeta a história ambiental? Sörlin (2011) supõe que o apelo da História Ambiental em tratar com o que ela considera como temas de maior pressão global servem para parametrizar esse foco. É assim que a história ambiental dos desastres pode emergir em meio a diferentes 
maneiras de se fazer HA, uma vez que a discussão em torno dos tecnodesastres, sua relação com a memória, com os processos de esquecimento e de lembrança, bem como, com corpos humanos vivos e mortos e o mundo natural têm constituído novos campos de pesquisa no âmbito da história ambiental

Assim, não é possível, por exemplo, falar de uma metodologia específica de história ambiental, na medida em que a própria interdisciplinaridade a ela inerente favorece a polifonia metodológica e teórico-interpretativa. Contudo, é ponto pacífico que a leitura das ações humanas em relação com o ambiente no passado significa a apropriação do ambiente como categoria, ou como filtro pelo qual toda a interpretação das escolhas sociais em termos de energia, de agricultura e de uso de recursos opera.

Christof Mauch e Helmut Trischler (2010), nesse sentido, afirmam que, na atualidade, há seis grandes grupos de convergência da preocupação em História Ambiental: uso de recursos e conservação; desastres naturais e cultura de risco; imperialismo ecológico; transformação das paisagens; ética ambiental e, por fim, conhecimento e sociedades do conhecimento (MAUCH e TRISCHLER, 2010).

Não é possível descolar a dimensão social de qualquer desastre, bem como sua dimensão tecnológica, uma vez que ele sempre é material e discursivamente construído, para além de sua organicidade. Isso pode ser amplamente percebido quando nos deparamos com narrativas de "correção da natureza", e como essa atitude pode ter mudado ao longo do tempo, ou nas narrativas deterministas tecnológicas. Nesse sentido é que a história e sua relação com os desastres tal qual a concebemos pode enfocar desastres não apenas em longas séries (o que acontece, muitas vezes, com pesquisas ligadas a desastres ditos “naturais"), como também no seu caráter de evento, com uma apreensão multifacetada.

Uma das dimensões de interesse no estudo de desastres tem sido a apreensão científica dos fenômenos, bem como a apreensão de quem o viveu, o que resulta na polifonia de racionalizações técnicas e tácitas em torno de um evento extremo (ALLEMEYER, 2007). Qualquer evento desastroso gera consequências socioeconômicas, imediatamente perceptíveis como negativas, proporcionam território para a formulação e 
disputa entre narrativas que reacendem topoi apocalípticos, religiosos ou seculares (GARRARD, 2005).

A trajetória social dos desastres atrela-se à contemporaneidade como junção de temporalidades no tapete da $\mathrm{HA}$, e suas narrativas caminham entre vitimização e heroísmo, por vezes enfadonhas porque repetitivas, mas também expressam mudanças significativas em suas formulações quando se desloca o evento no tempo e no espaço, especialmente a partir da ideia de vulnerabilidade e, nesse sentido, a contaminação de Césio-137 em Goiânia, analisada a seguir, permite-nos pensar essas articulações.

\section{A contemporaneidade de um desastre, o tempo presente do risco: Césio- 137 em Goiânia}

Goiânia, entre setembro e outubro de 1987. Dois homens descobriram, transportaram, desmontaram e venderam partes de uma máquina de radiologia abandonada num prédio em ruínas do antigo Instituto Goiano de Radiologia em terreno que estava sub judice, para um depósito de ferro-velho de propriedade de Devair Ferreira (Veja, 1987a). Tudo isso aconteceu entre 13 e 18 de setembro. Ferreira, por sua vez, decidiu romper um cilindro que fazia parte da máquina e ficou encantado com um pó que, à noite, emitia brilho azul celeste (cloreto de césio).

O pó tornou-se motivo de curiosidade, e de encantamento pela família e amigos de Ferreira. Manuseado, doado e até ingerido, em poucos dias a família começou a notar problemas de saúde em comum, tais como náuseas, tontura e dores que não tinham explicação aparente, a não ser o contato com aquele pó. Por insistência de Gabriela Ferreira, o restante do cloreto de césio que havia em casa foi transportado até a sede da Defesa Civil do município, por meio de ônibus urbano, chegando ali em 28 de setembro, acompanhado dos relatos familiares. Quase que de imediato, o físico Walter Mendes Ferreira constatou que o pó era radioativo. Tinha início oficial, ali, a história do maior desastre radioativo mundial civil, fora de uma usina.

Os episódios oficiais do evento vão da localização da máquina abandonada em 13 de setembro até o final da descontaminação operada pela Comissão Nacional de Energia 
Nuclear (CNEN), com o lixo radioativo sendo depositado no distrito de Abadia de Goiás (que veio a ser emancipado em 1995). À época, essa história ainda carregou episódios insólitos, tais como a multidão enfurecida que protestava contra o enterro da primeira vítima do acidente, a menina Leide das Neves Ferreira, então com seis anos, no cemitério de Goiânia, cujo caixão revestido de chumbo e pesando mais $700 \mathrm{~kg}$ foi alvo de pedras, pedaços de madeira e cruzes arrancadas daquele local (VEJA, 1987C). Outro episódio foi o de disputa e protestos em torno da definição de local para o lixo radioativo resultante do acidente, que mobilizou indígenas do Pará (já que o governo tinha uma primeira proposta de levar os rejeitos para a Serra do (achimbo), bem como a população de Goiânia e do distrito de Abadia de Goiás.

A história do desastre, contudo, continua, especialmente quando pensamos: a) que o depósito de lixo radioativo, que era provisório, tornou-se oficialmente permanente apenas em 1997, dentro do Parque Estadual Telma Ortegal, criado para dar Ihe dar suporte; b) que a justiça começou a conceder pensões de maneira liminar em prazos muito distantes do evento, a partir de 2012 e que o Estado de Goiás e a União ainda contestam diversos elementos jurídicos da questão, tais como prazos prescricionais e responsabilidade e, especialmente; c) que o evento ainda é disputado entre memória, trauma, elaboração, ressentimentos, narrativas diversas que mostram tensões entre indivíduos vitimados e Estado.

Telma Camargo da Silva (2010) observa que desastres, mais do que eventos localizados, rompem a teia dos significados mais restritos ao evento, expandindo-se em narrativas mais amplas. No caso específico de tecnodesastres como o de Goiânia, isso fica evidente, especialmente porque o caráter episódico de distúrbios que venham a ser considerados como desastres, conforme pontua a historiadora Ursula Lehmkuhl (2007, p. 13), fazem com que a natureza adquira qualidade de agência histórica e, com isso, poder. No caso de Goiânia, ela pode ter se manifestado na medida em que isótopos liberados na atmosfera atingiram corpos humanos e não humanos, alterando sua estrutura celular, de maneira invisível, improvável ou não calculada, do ponto de vista da crença na tecnologia. Nesse sentido, é fundamental pensarmos que desastres reais podem ser contrastados com suas representações em conjuntos de percepção social sobre fenômenos extremos 
que vão desde lendas à ficção científica e que podem vir a direcionar questões sobre em que medida uma "cultura do desastre" (DAVIS, 1998; KEANE, 2001) estabelece preconceitos sobre a visão de catástrofe (MEIER, 2007). Um desastre, nesse sentido, é material, social e discursivamente construído (SCHENK, 2007), tendo a vulnerabilidade como não apenas um modo de determinar as condições inseguras do presente como também um importante meio de descrever como as populações são expostas a ela.

Em 7 de outubro de 1987, Veja publicou a primeira reportagem sobre o tema, “Brilho Perigoso" (VEJA, 1987a, p. 30), narrando os momentos iniciais do "gravíssimo acidente nuclear", informando o número de vítimas oficiais, observando que várias pessoas estavam mantidas em quarentena no Estádio Olímpico de Goiânia. Em alguns setores da cidade, "uma onda de pânico tomou conta da população e milhares de pessoas começaram a abandonar suas casas" (VEJA, 1987a, p. 30). Ao cobrir as consequências imediatas e as vítimas mais graves da contaminação, a revista lembrava que "[...] o mesmo material que servira um dia para curar, provocou uma devastação pelo excesso de exposição das pessoas ao elemento radioativo" (VEJA, 1987a, p. 30).

Logo, outros periódicos já descreveriam o desastre como "o pior acidente do mundo" (REALI JR, 10 out. 1987, p. 10). A enxurrada de matérias sobre o desastre aconteceu naquela mesma semana, com publicações nos principais jornais brasileiros e internacionais ${ }^{2}$. A Revista Veja retornou ao tema na edição seguinte, em 14 de outubro, agora construindo sua leitura do desastre urbano de Goiânia, informando que,

Para quase 1 milhão de moradores de Goiânia, instalou-se o desconforto pavoroso de conviver com uma ameaça cujas dimensões as autoridades estão tendo dificuldade para precisar - e ainda mais para comunicar suas conclusões à população. [...] Para o morador de Goiânia ainda não está claro se sua cidade tornou-se inabitável, se foi palco de uma tragédia cujos efeitos mais desastrosos ainda se vão desenrolar ou se, passado o susto, as coisas tendem a normalização. (VEJA, 1987b, p. 58)

\footnotetext{
2 Elencamos aqui apenas três reportagens, uma no Brasil e duas nos EUA, para exemplo: Reali Junior. Goiânia, "pior acidente do mundo". O Estado de São Paulo, p. 10. Sábado, 10 de outubro de 1987; O GLOBO. Goianenses vão à rua em protesto. Disponível em: $<$ https://www.instagram.com/memorialdademocracia/>; SIMONS, M. Radiation fears infect Brazil after accident. The New York Times. New York: TNYT, 2 dez. 1987. SIMONS, M. Goiania Journal; Gittering toy delights and does its deadly work. The New York Times. New York: TNYT, 19 out. 1987. SIMONS, M. Brazil gets help on radiation accident. The New York Times. New York: TNYT, 11 out. 1987.
} 
A revista voltou a abordar o tema apenas nas quatro semanas seguintes. Depois disso, a atenção foi ficando cada vez mais tímida e o que tinha desmobilizado estruturas sociais e comunitárias veio a assumir, paulatinamente, a característica de um acidente. Apesar de intensa visibilidade dos primeiros momentos do desastre, o silenciamento sobre ele não demorou a habitar as páginas da imprensa nacional em prazo relativamente curto. No ano seguinte, foi publicada uma reportagem em fevereiro, que falava da criação de um bloco de carnaval organizado por algumas vítimas do acidente e nada era falado sobre a situação dessas vítimas em termos de políticas públicas de acesso à saúde.

No restante do ano, três menções foram encontradas a respeito do acidente. $O$ Césio-137, que destroçou vidas e hábitos, que removeu famílias de suas casas e depois destruiu as próprias casas, ganhava o tratamento de acidente, normalizado socialmente. A narrativa do acidente ganhava força em meio à desinformação sobre o que estava acontecendo até por parte das equipes que estavam trabalhando na sua contenção (WOJTOWICZ, 1990, p. 20).

A jornalista Ana Wojtowicz (1990) e a antropóloga Telma Camargo da Silva (2010), em diferentes momentos e com diferentes lentes, trataram da relação conflituosa entre o silêncio das instituições, o estabelecimento da supremacia narrativa do saber médico e de saúde sobre outros saberes, bem como os processos de pressão que a informação ou falta dela representam para o mundo das relações sociais que vieram a surgir em torno do evento. Wojtowicz (1990), por exemplo, buscou dar visibilidade ao desconforto que os principais personagens sentiram com relação às primeiras notícias do evento (WOJTOWICZ, 1990, p. 20). Ela também trabalhou com as autoridades e pessoal convocado para o processo de descontaminação de Goiânia; mais de 300 pessoas, que trabalharam sem saber o que estava acontecendo, sendo a maioria irradiados ao longo do processo, entre setembro e dezembro de 1987 (WOJTOWICZ, 1990, p. 20). Paralelamente a isso, o discurso das autoridades nacionais era o de que, em 30 de setembro, todos os focos de contaminação já estavam identificados e o controle do processo em vias de se efetivar rapidamente.

O desastre de Goiânia, nesse sentido, de acordo com Telma Camargo da Silva (2010), rompeu ordens culturais, políticas e econômicas e expôs a vulnerabilidade de 
grupos sociais locais ao se defrontar com as consequências danosas da tecnologia nuclear. A principal delas foi, certamente, de ordem biológica, diretamente nos corpos de vítimas fatais ou na verificação dos fenômenos biológicos corporificados, o que, em certa medida, viabilizou uma representação da radioatividade, possibilitando, então, nomear e categorizar suas implicações mais diretas (HELOU, COSTA NETO e CURADO, 2015, p. 98).

Uma vez qualificado, nomeado e efetivamente representado, o evento veio a prejudicar a economia local de Goiânia (produtos rejeitados nacionalmente), assim como seus habitantes, que sofreram discriminação e tinham de requerer documentos assinados pela CNEN para viajar para fora da cidade; carros com placas de Goiânia eram apedrejados; a administração pública municipal teve que reorganizar as finanças devido à canalização de recursos para a saúde. Além disso, expôs-se a inadequação da legislação nuclear brasileira, que criara ações conflitantes na CNEN, como formulação e planejamento de política nuclear nacional, além de ter de agir como reguladora, gerenciadora, fiscalizadora e monitoradora do tema (SILVA, 2010).

Três anos depois, Ana Wojtowicz (1990) começou a discutir as consequências mais profundas, cotidianas e subjetivas do césio-137 em Goiânia. Nesse sentido, como jornalista, buscou contatar e acessar vítimas diretas do processo, tais como Devair Ferreira e alguns de seus familiares, apresentando suas falas, seus dilemas, suas perspectivas (ou ausência delas) assim que o processo de descontaminação foi realizado. As vozes apresentadas por ela mostravam que a extensa família de Ferreira tornara-se um grupo intensamente controlado, especialmente pelo binômio Estado-Medicina. Ao entrevistar Devair Ferreira, por exemplo, que reclamava da falta de informações e de preparo da própria equipe que trabalhou no processo de descontaminação, ele afirmava que "nós somos cobaias até hoje. E vamos continuar sendo pro resto da vida" (WOJTOWICZ, 1990, p. 83). Luisa Odete dos Santos relatou à jornalista que "tem hora que eu sinto mesmo [que sou cobaia]. [...] No início era uns médicos que cuidavam da gente; hoje são vários que querem cuidar..." (WOJTOWICZ, 1990, p. 98).

No mesmo período, Claudia Palestino observa que o governo federal e o Estado de Goiás concediam as primeiras pensões para todas as vítimas diretas do acidente (os grupos 1 e 2, qualificados pelo saber médico). 
Em 1990, o filme Césio 137: o pesadelo de Goiânia, dirigido por Roberto Pires (mais tarde vítima do próprio desastre), dramatizou o evento, construindo e consolidando algumas narrativas já presentes na mídia impressa, incorporando religiosidade, pobreza, ignorância numa narrativa que mostrava a descoberta da máquina, sua destruição e a instalação do caos em virtude do pó azul, até o transporte dele, depois de causar problemas, para ser analisado junto à Vigilância Sanitária de Goiânia. A ênfase recaía no papel significativo de Gabriela (Joana Fomm) na descoberta do Césio-137 e os dilemas da família de Devair Ferreira (Nelson Xavier) logo após a descoberta da contaminação (PIRES, 1990).

O silenciamento em torno do evento foi constatado por diferentes campos do conhecimento. Vinte anos depois do desastre, uma pesquisa multidisciplinar, envolvendo as áreas da Psicologia e do Serviço Social apontavam para o seguinte quadro: "os pacientes ainda carregam o sofrimento decorrente do preconceito e da discriminação social em função do acidente, embora hoje, constate-se o desconhecimento da sociedade sobre [ele]" (PALESTINO e DIAS, 2015, p. 120-135).

Goiânia passou a viver uma relação específica com o Césio-137, na qual datas alusivas ao evento serviram para produzir mecanismos de esquecimento cada vez mais sutis, porém midiáticos. Em 2012, por exemplo, o governo do estado lançou a Revista Césio-137 25 anos, estampando na capa a imagem de Leide das Neves Ferreira, primeira vítima fatal do evento, e que, ainda no final daquele ano de 1987, tornou-se homenageada com a criação da Fundação Leide das Neves, para o atendimento de radioacidentados.

O mote da publicação era "uma história pra relembrar e prevenir", começando pela entrevista com um dos primeiros médicos envolvidos no processo de delimitação e interdição dos focos do acidente, em 1987, Antonio Faleiros, passando pela lembrança dos sobreviventes e, finalizando, com a publicação de um boletim epidemiológico sobre o Césio-137 (GOVERNO DO ESTADO DE GOIÁS, 2012).

O editorial da revista, "Césio 25 anos depois" descreve o acidente a partir dos mesmos motivos já apresentados pela Veja e por outras publicações do período. Contudo, abre-se um horizonte no qual "a tragédia não pode ser esquecida", em que "o 
césio-137 deixou cicatrizes que o tempo não consegue apagar" (GOVERNO DO ESTADO DE GOIÁS, 2012). O texto caminhava no sentido de estabelecer uma cristalização do desastre no passado, em 1987, na medida em que, nas palavras do então Secretário de Estado da Saúde, Antonio Faleiros Filho, salientava que "rendemos nossas homenagens às vítimas e a todos os envolvidos direta ou indiretamente no trabalho de descontaminação de Goiânia. Heróis que arriscaram a própria vida para devolver a tranquilidade a um povo que, com muita coragem e solidariedade, enfrentou o perigo totalmente desconhecido" (GOVERNO DO ESTADO DE GOIÁS, 2012).

Depois de 25 anos do desastre, o depósito permanente do lixo nuclear em Abadia de Goiás mudava, também, sua forma, com a garantia da invisibilidade das caixas amarelas a partir da cobertura vegetal em formato de pequenos montes. A revista não deixava de positivar o espaço destinado ao lixo nuclear de Goiânia, o Parque Estadual Telma Ortegal. O então distrito de Abadia de Goiás foi emancipado em função do depósito e o espaço que era de temor, ainda no final dos anos 1980, foi apropriado pelo discurso estatal nos seguintes termos:

Lá, plantando, tudo dá. São dezenas de goiabeiras, cajueiros, jabuticabeiras, pés de manga e de acerola. As hortas, 100\% orgânicas, produzem alface, couve, coentro, cebolinha e hortelã. Nem é preciso fazer silêncio para ouvir o canto de pássaros típicos do Cerrado, mas é preciso estar atento para não perder as acrobacias de macaquinhos e outros animais da fauna nativa, que se deslocam muito à vontade pelo local. Os córregos Quati e Dourado são um convite à pesca e favorecem a produção de hortaliças, mesmo no quente e seco inverno goiano. (GOVERNO DO ESTADO DE GOIÁS, 2012, s/p)

A reportagem, construindo uma espécie de paisagem pastoral em meio ao cerrado, com imagens vívidas de harmonia entre sociedade e mundo natural, apresentava uma natureza quase prístina aos olhos desatentos ao prenúncio de um depósito nuclear. De maneira involuntária, esse tipo de narrativa invocava parte de um repertório já muito bem discutido pela ecocrítica (PURDY, 2015), no qual cenários mais obscuros em termos de problemas ambientais são precedidos pela narrativa de um status quo anterior de harmonia, de felicidade, de plenificação da natureza na vida humana. 
No parágrafo seguinte, é importante notar que todo o cenário idílico que remete a leitura para os aromas, as cores, sabores, movimentos e riqueza faunística e florística da paisagem do Cerrado reverte-se numa sequência de acontecimentos técnicos, de experiências de indivíduos e instituições importantes que comemoram a criação do parque não para a contemplação da natureza, mas para o acondicionamento de rejeitos radioativos:

A área, de 1.600 mil metros quadrados, que faz divisa com os municípios de Guapó, Trindade, Aparecida de Goiânia e a capital, Goiânia, poderia ser uma região de preservação ambiental como outra qualquer, mas é o parque que abriga o depósito definitivo dos rejeitos radioativos gerados pelo acidente com o Césio 137. Inaugurado em 5 de junho de 1997, pelo governador da época, Maguito Vilela (PMDB), o Secretário de Assuntos Estratégicos, Ronaldo Sadenberg e o Presidente da Comissão Nacional de Energia Nuclear (Cnen), José Mauro Esteves dos Santos, entre outras autoridades, o depósito deixou então a condição de "provisório" para se tornar "definitivo". (GOVERNO DO ESTADO DE GOIÁS, 2012, s/p).

Cristina H. Gomide (2015), em obra organizada sobre as consequências psicossociais do evento, observa que "o que mais intriga é que a cidade foi revitalizada e estamos entre uma das cidades brasileiras melhor arborizadas e mais ecologicamente corretas. No entanto, nossa memória é a do silêncio e nossa história a do esquecimento" (GOMIDE, 2015).

A observação apresentada pela autora precisa ser enfatizada, em termos de contemporaneidade da experiência do desastre, na articulação com a narrativa do episódio do depósito do lixo radioativo resultante do processo de descontaminação já citado, no sentido de podermos pensar a dimensão material do silenciamento e da invisibilidade que o desastre vai tomando com o passar dos anos.

$\mathrm{Na}$ imagem 1 verifica-se o estabelecimento do depósito provisório que foi instalado em 1987, em meio ao desenvolvimento imediato do desastre, porém depois de inúmeros embates ligados à localização precisa dos rejeitos. Trata-se de um espaço a céu aberto, em meio ao Cerrado brasileiro, no qual contêineres e outros itens começavam a ser estacionados sob esquema de segurança, desenhando, contudo, uma paisagem visível de blocos em cima de plataformas de concreto e cobertos com lonas de cor característica. 
Imagem 1: Depósito provisório de lixo radioativo em Abadia de Goiás, distrito de Goiânia, em 1987.

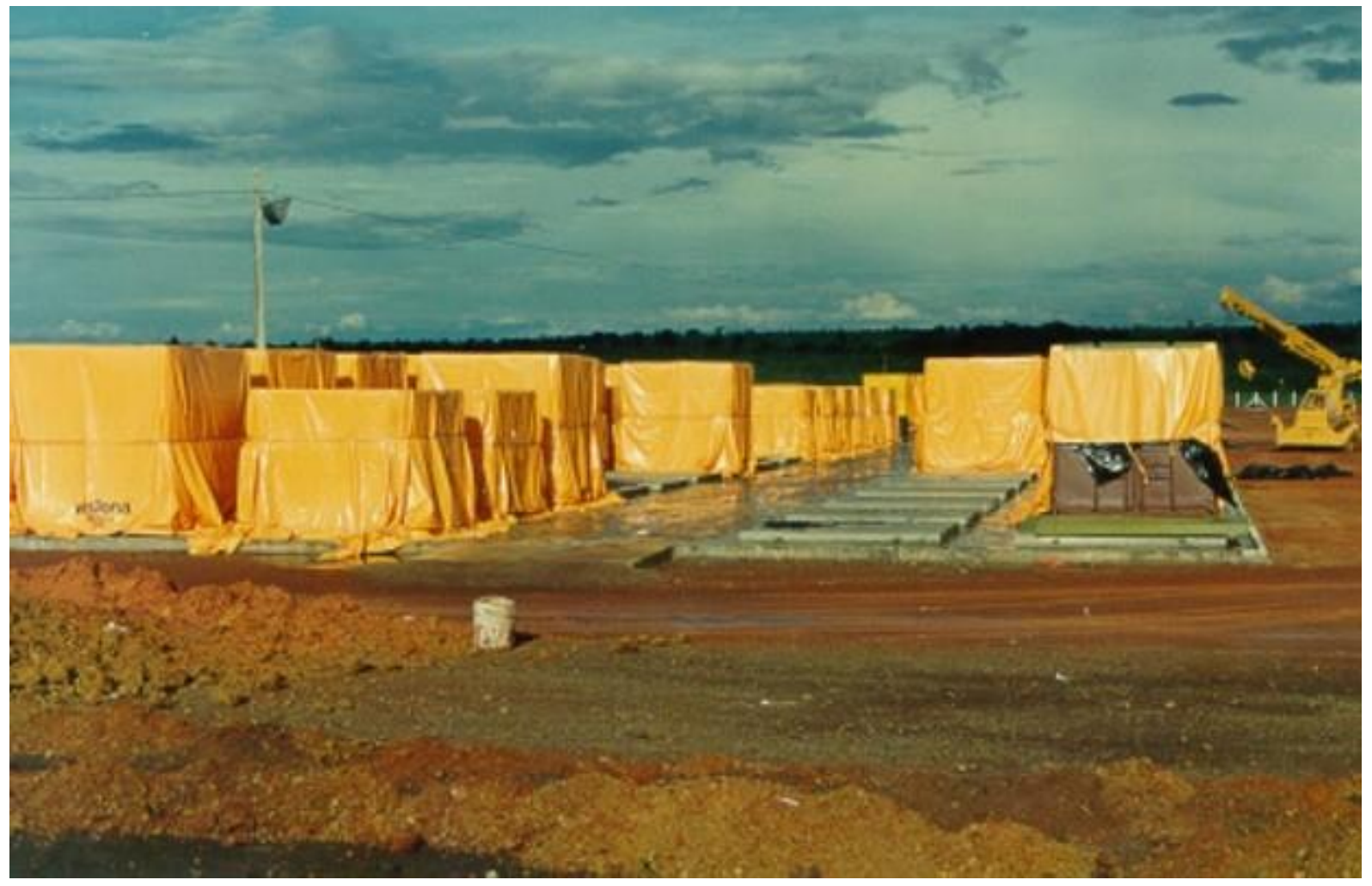

Fonte: REVISTA EMERGÊNCIA. Depósito de rejeitos do césio-137 foi alvo de polêmica em GO. Disponível em: http://www.revistaemergencia.com.br/noticias/ocorrencias/deposito_de_rejeitos_do_cesio137_foi_alvo_de _polemica_em_go/A5jyJgji. Acesso em: 5 set. 2018.

O Cenário da imagem 1 destoa radicalmente da paisagem que, no mesmo espaço, foi construída anos depois, quando o depósito passou de "provisório" para “permanente” (Imagem 2). Agora, não mais havia contêineres enfileirados a céu aberto; não era possível vivenciar a experiência de ver os rejeitos destoando de uma paisagem típica do Cerrado, como construção humana.

Em certa medida, considerando o processo de emancipação de Abadia de Goiás, o de constituição do Parque Estadual Telma Ortegal para acomodar o lixo nuclear, o estacionamento de Polícia Militar Ambiental, a construção de um centro de pesquisas no local, foi-se elaborando, de maneira simultânea, a desobjetificação do rejeito sob a maneira de contêineres (de produto humano) em razão de uma nova paisagem "naturante", na medida em que foram enterrados, retirados das vistas públicas, desmaterializados a partir de uma estratégia simbólica e ao mesmo tempo técnica e prática, de enterramento (Imagem 2). 
Imagem 2: atual situação do depósito radioativo de Abadia de Goiás/GO.

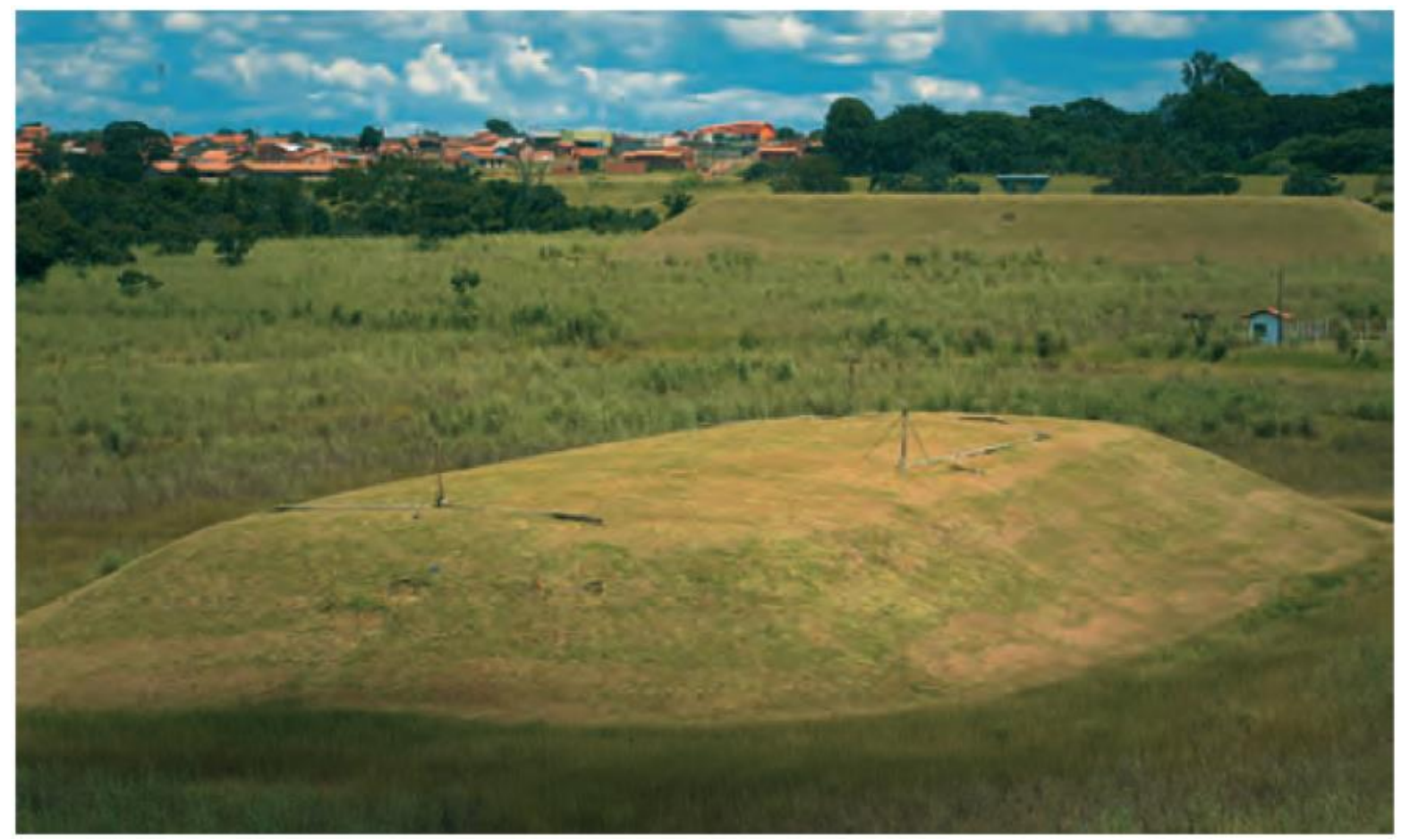

Fonte: DUTRA, K. Césio-137: 30 anos da maior tragédia radioativa do Brasil. Redes. Disponível em: http://redes.moderna.com.br/2017/04/17/30-anos-acidente-radioativo-cesio-brasil/. Acesso em: 8 set. 2018.

Certamente, contudo, o enterramento do acidente, a desmaterialização do lixo nuclear como resultado da própria materialização do depósito definitivo não conseguiria dar por encerrada uma história de muitas temporalidades e sempre ditada na disjunção entre o tempo de 1987 e o presente da memória de vítimas e que passará, das narrativas da imediatez do evento dadas pela mídia impressa ainda nos primeiros anos pós-desastre, para relatos de memórias mais densos, multiplamente midiatizados, mais corporificados com o passar dos anos.

A partir dos anos 2000, dois documentários, um dirigido em 2003 por Luis Eduardo Jorge, intitulado Césio 137 - O Brilho da Morte, e outro organizado em quatro episódios com título semelhante (O Brilho da Morte - 30 anos do Césio 137) exibido em 2017, construíram novos relatos, expuseram novas memórias, revisitaram outras mais antigas, deram luz a novos personagens e imagens de episódios importantes do desastre. No caso do primeiro documentário, colagens de imagens e eventos radioativos históricos desde os anos 1950 intercalam-se ao desenrolar dos relatos de vítimas diretas do desastre de Goiânia. 
No segundo, trata-se da visibilidade de relatos de vítimas diretas e indiretas do evento, muitas delas já ligadas à Associação das Vítimas do Césio-137, imbuídas da fala autorizada (porta-vozes) das lutas pelo reconhecimento de vítimas imediatas e ainda presentes. O depoimento de Teodoro Juvenal, que à época do evento trabalhava como mecânico numa empresa estatal de infraestrutura e que convocou todos os funcionários para atuarem na descontaminação, sem que soubessem do que se tratava, relata, ao fim do documentário o seguinte: “Nós estamos mortos; só falta enterrar. Tem muita pessoa que fala que homem não chora. Mas todo homem chora [...] e chora pela exclusão, quando você chega num grupo e o grupo corre de você" (JUVENAL apud ROSA, 2017).

\section{Considerações finais: o tempo presente do Césio-137 e a contemporaneidade como disjunção do tempo passado}

Desastres são incessantemente contados e recontados em noticiários, filmes, contos, óperas, jogos de computador, parques ou museus. A miríade de histórias sobre desastres está estruturada num número limitado, porém, de formas narrativas e de motivos, tais como teodiceia, apocalipse, estado de exceção, trauma, e esse repertório de modelos culturais não apenas estrutura como nós, hoje, imaginamos e lemos desastres mas também como podemos controlá-los, manejá-los. Nesse sentido, histórias de desastres como o de Goiânia, em 1987, são um modelo para, e de, práticas sociais da contemporaneidade.

Vítimas legitimadas ou não, desde 1987, têm falado de suas experiências, contribuindo para a formulação de um entendimento do risco, afetando diretamente a construção de sua história no presente. O que o Césio-137, de Goiânia, em 1987, e suas representações nos falam sobre o entendimento das relações entre passado, presente e futuro na história do tempo presente?

Em primeiro lugar, a contínua retomada das narrativas em torno do desastre que vieram a ser consolidadas, tais como a da vitimização devido à pobreza e ignorância dos agentes, ou a da inconstância e falibilidade das instituições de fiscalização nuclear proporcionam chave interessante para se pensar o contemporâneo como horizonte de 
experiência de quem viveu aquele desastre, mas também como mesmo horizonte para quem vive qualquer desastre. No segundo momento, a realocação dessas mesmas narrativas num mundo cristalizado e imóvel do passado, inclusive com a instrumentação material de paisagens de silenciamento, como é o caso da transformação do depósito de lixo nuclear temporário em depósito permanente, em Abadia de Goiás (em 1997), localizado agora num parque estadual que escondeu contêineres, caixas e demais itens das vistas de qualquer pessoa na forma de pequenas elevações no relevo plano, muito bem cobertas pela vegetação, construindo, efetivamente, paisagens de ausência mais do que paisagens de visibilidade (Uma história de paisagens pretéritas para um tempo presente?)

A contemporaneidade, nesse sentido, promove a junção do tecido estrutural da história com as temporalidades sobrepostas de eventos desastrosos, por exemplo, ao mesmo tempo se constitui como uma unidade disjuntiva de tempos (o tempo do passado em virtude do tempo do futuro, inscritos no presente), no qual traumas, experiências, ao mesmo tempo em que parecem emergir a todo instante em diferentes mídias, referendam a tensão entre as vozes que falam, as vozes que sussurram e as vozes que silenciam (autoridades) na temporalidade das efemérides (10, 25, 30 anos) e na temporalidade de 1987.

O Césio-137 é um exemplo, nesse sentido, das aproximações entre HA e HTP por meio da contemporaneidade do problema da memória, da experiência, da elasticidade temporal de uma datação restrita de um evento extremo, das tensões que emergem quando as profundas consequências corporificadas e biológicas da irradiação de um isótopo precisam ser lidas, enunciadas, pela política e pela subjetividade de vítimas, no emaranhamento do tempo presente. 


\section{Referências}

ALLEMEYER, Marie L. Profane hazard or divine judgment? Coping with urban fire in the 17th. century. Historical Social Research, Köln, v. 32, n. 3, p. 145-168, 2007.

AREND, Silvia. M. F.; MACEDO, Fábio. Sobre a história do tempo presente: entrevista com o historiador Henry Rousso. Tempo \& Argumento, Florianópolis, v.1, n.1, p. 201-216, jan./jun. 2009.

BARRACLOUGH, Geoffrey. An introduction to contemporary history. Middlesex: Penguin Books, 1969.

BUELL, Lawrence. Writing for an endangered world. Boston: Belknap Press, 2001.

CLARK, Timothy. Ecocriticism on the edge: the anthropocene as a thershold concept. London: Bloomsbury, 2015.

DAVIS, Mike. Late victorian holocausts: el niño famines and the making of the third world. London/New York: Verso, 2001.

DUTRA, Katia. Césio-137: 30 anos da maior tragédia radioativa do Brasil. Redes. Disponível em: http://redes.moderna.com.br/2017/04/17/30-anos-acidente-radioativo-cesio-brasil/. Acesso em: 8 set. 2018.

GADAMER, Hans-Georg. Verdade e método: traços fundamentais de uma hermenêutica filosófica. 3.ed. Petrópolis: Vozes, 1999.

GARRARD, Greg. Ecocrítica. Brasília: Editora da UnB, 2005.

GERBER, Doris. Causal Explanation and Historical Meaning: How to Solve the Problem of the Specific Historical Relation Between Events. In: KAISER, Marie I.; SCHOLZ, Oliver R.; PLENGE, Daniel; HÜTTEMANN, Andreas. (Orgs.). Explanation in Special Sciences: the case of biology and history. Heidelberg: Springer, 2014. p. 197-210.

HARAWAY, Donna. The Companion Species Manifesto: dogs, people, and significant otherness. Chicago: Prickly Paradigm Press, 2003.

GOVERNO DO ESTADO DE GOIÁS. Revista Césio 25 anos. Goiânia: Governo de Goiás, 2012.

HELOU, Suzana; COSTA NETO, Sebastião B. da. (Orgs.). Césio-137: consequências psicossociais do acidente de Goiânia. Goiânia: UFG Digital, 2015.

HELOU, Suzana; COSTA NETO, Sebastião B. da; CURADO, Maria P. Análise psicossocial da população de Goiânia três anos após o acidente com o césio-137. In: HELOU, Suzana; COSTA NETO, Sebastião B. da. (Orgs.). Césio-137: consequências psicossociais do acidente de Goiânia. Goiânia: UFG Digital, 2015. p.85-104. 
ISENBERG, Andrew C. The Oxford handbook of environmental history. New York: Oxford University Press, 2014.

JORGE, Luís E. Césio 137: o brilho da morte. 2003. Documentário. 1h33min. color.

KEANE, Stephen. Disaster movies: the cinema of catastrophe. New York: Walflower, 2001.

KLIPP, Suzana. Ethicidades televisivas. São Leopoldo: Unisinos, 2002.

KOMEL, Dean. Gadamer and Kierkegaard: On contemporaneity. Filozofia, Praha, v. 69, n. 5, p.434-442, 2014.

LATOUR, Bruno. Políticas da natureza. Bauru: EDUSC, 2004.

LEHMKUHL, Ursula; WELLENREUTHER, Helmuth. Historians and nature: comparative approaches to environmental history. Oxford: Berg, 2007.

MATURANA, Humberto. Cognição, ciência e vida cotidiana. Belo Horizonte: Editora da UFMG, 2001.

MAUCH, Christof.; TRISCHLER, Helmut. International Environmental History. Munich: RCC Perspectives, 2010.

MEIER, Mischa. Zur Terminologie der (Natur-)Katastrophe in der griechischen historiographie: einige einleitende Anmerkungen. Historical Social Research, Köln, v. 32, n. 3, p. 44-56, 2007.

O GLOBO. Goianenses vão à rua em protesto. Disponível em:_ttps://www.instagram.com/ memorialdademocracia.

PALESTINO, Claudia S. F.; DIAS, Fabiana do P. Aspectos sociais dos vinte anos desde o acidente radiológico com o césio-137. In: HELOU, Suzana; COSTA NETO, Sebastião B. da. (Orgs.). Césio-137: consequências psicossociais do acidente de Goiânia. Goiânia: UFG Digital, 2015. p.120-133.

PÁDUA, José A. As bases teóricas da história ambiental. Estudos Avançados, São Paulo, v.24, n.68, p.81-101, 2010. DOI: http://dx.doi.org/10.1590/S0103-40142010000100009.

PIRES, Roberto. Césio 137: o pesadelo de Goiânia. Rio de Janeiro: Globo, 1990. 115min. colorido.

PURDY, Jedediah. After nature: a politics for the anthropocene. Cambridge: Harvard University Press, 2015. 
REALI JUNIOR. Goiânia, "pior acidente do mundo". O Estado de São Paulo, p.10, 10 de outubro de 1987.

REVISTA EMERGÊNCIA. Depósito de rejeitos do césio-137 foi alvo de polêmica em GO. Disponível em:

http://www.revistaemergencia.com.br/noticias/ocorrencias/deposito_de_rejeitos_do_ces io137_foi_alvo_de_polemica_em_go/A5jyJgji. Acesso em: 5 set. 2018.

ROSA, Jordevá. O brilho da morte: 30 anos do césio 137. Goiânia: SBT-Serra Dourada, 2017. 4 episódios. 23min.

ROTENSTREICH, Nathan. Time and meaning in history. Boston: D. Reidel Publishing Company, 1987.

SCHÄFER, Wolff. Global history and the present time. Center for Global History and Local History. Stony Brook: SBU, 2018. Disponível em:

https://www.stonybrook.edu/globalhistory/PDF/

GHAndThePresentTime.pdf

SCHENK, Gerrit J. Historical disaster research: state of research, concepts, methods and case studies. Historical Social Research, Köln, v. 32, n. 3, p. 9-31, 2007.

SILVA, Telma C. da. Eventos críticos: sobreviventes, narrativas, testemunhos e silêncios. Anais RBA, 27. Disponível em: http://www.abant.org.br/conteudo/ANAIS/CD_Virtual_27_RBA/arquivos/ grupos_trabalho/gt20/tcs.pdf. Acesso em: 13 ago. 2018.

SIMONS, Marlise. Radiation fears infect Brazil after accident. The New York Times, New York: TNYT, 2 dez. 1987.

SIMONS, Marlise. Goiania Journal; Gittering toy delights and does its deadly work. The New York Times, New York: TNYT, 19 out. 1987.

SIMONS, Marlise. Brazil gets help on radiation accident. The New York Times, New York: TNYT, 11 out. 1987.

SMITH, Terry. Defining contemporaneity: imagining planetarity. The Nordic Journal of Aesthetics, Aarhus, v. 24, n. 49-50, p. 156-174, 2016.

SOUZA, Lourdes. 25 anos após césio 137, Justiça condena Estado de Goiás a pagar pensão a cinco trabalhadores. UOL Portal. Disponível em: https://noticias.uol.com.br/cotidiano/ultimas-noticias/2012/10/10/25-anos-apos-cesio-137justica-condena-estado-de-goias-a-pagar-pensao-a-cinco-trabalhadores.htm. Acesso em: 11 out. 2018. 
SÖRLIN, Sverker. The contemporaneity of environmental history: negotiating scholarship, useful history, and the new human condition. Journal of Contemporary History, v. 46, n. 3, p. 610-630, 2011.

VEJA. Brilho perigoso. São Paulo: Abril. Edição 996, 7 out. 1987. p.30.

VEJA. Desolação radioativa. São Paulo: Abril. Edição 997, 14 out. 1987. p.58.

VEJA. Inocentes de plantão. São Paulo: Abril. Edição 998, 21 out. 1987, p.36.

VIEREGG, Hildegard. K. Contemporary history in relation to memory, museums and memorial sites internationally - past, present and future. Complutum, Madrid, v. 26, n. 2, p. 89-99, 2015.

WOJTOWICZ, Ana L. Roubados em seus sonhos: uma interpretação da cobertura jornalística do acidente com o Césio 137 em Goiânia. Brasília: UnB, 1990.

Recebido em 30/09/2018

Aprovado em 14/02/2019

Universidade do Estado de Santa Catarina - UDESC

Programa de Pós-Graduação em História - PPGH

Revista Tempo e Argumento

Volume 11 - Número 26 - Ano 2019 tempoeargumento@gmail.com 